\title{
The association of metabolic syndrome components and diabetes mellitus: evidence from China National Stroke Screening and Prevention Project
}

Wenzhen Li ${ }^{1}$, Dongming Wang ${ }^{2}$, Xiaojun Wang ${ }^{1}$, Yanhong Gong ${ }^{1}$, Shiyi Cao ${ }^{1}$, Xiaoxv Yin ${ }^{1}$, Xianbo Zhuang ${ }^{3}$, Wenhuan $\mathrm{Shi}^{4}$, Zhihong Wang ${ }^{5,6^{*}}$ and Zuxun $\mathrm{Lu}^{1 *}$ (D)

\begin{abstract}
Background: The metabolic syndrome (MetS) is related with cardiovascular disease. However, its relationship with diabetes mellitus (DM) has not been examined in Chinese population with a larger sample. We aimed to assess the relationship between metabolic syndrome (MetS) and its components, and DM, and to determine the best one from the available definitions of Mets when assessing the risk of DM.

Methods: This was a cross-sectional survey in a nationally representative sample of 109,551 Chinese adults aged $\geq 40$ years in 2014-15. MetS was defined according to three criteria including the updated International Diabetes Federation (IDF) criterion, the National Cholesterol Education Program Third Adult Treatment Panel (NCEP ATP III) criterion and American Heart Association/National Heart, Lung, and Blood Institute (AHA/NHLBI) criterion. Logistic regression models were used to estimate the odds of DM.

Results: MetS as defined by three criteria including IDF, NCEP ATP III,and AHA/NHLBI all increased the prevalence of DM, and the adjusted ORs with 95\% CI was more higher using NCEP ATP III $(3.65,3.52-3.79)$ than IDF $(2.50,2.41-2.60)$ and AHA/NHLBI $(3.03,2.92-3.24)$. The odds of DM was highest in hyperglycemia with cut-off glucose $\geq 6.1 \mathrm{mmol} / \mathrm{L}$ $(14.55,13.97-15.16)$, and other components were also associated significantly with DM. There was heterogeneity for OR of DM associated with various trait combinations.

Conclusions: The NCEP ATPIII MetS definition may be more suitable for assessment of DM risk in Chinese population. Hyperglycemia, as previous study reported, are important risk factors of DM. Besides, other traits of Mets are also significantly associated with DM and should therefore be of greater concern.
\end{abstract}

Keywords: Metabolic syndrome, Diabetes mellitus, National cross-sectional study

\section{Background}

The prevalence of diabetes mellitus (DM) for all agegroups worldwide was estimated to be $4.4 \%$ (366 million) in 2030, and in China, the total number of people with DM will rise to 42.3 million [1]. Although no cure

\footnotetext{
* Correspondence: 247506385@qq.com; zuxunlu@yahoo.com

${ }^{5}$ Health Science Center, Shenzhen second people's hospital, The First Affiliated Hospital of Shenzhen University, Shenzhen 518020, People's Republic of China

${ }^{1}$ Department of Social Medicine and Health Management, School of Public Health, Tongji Medical College, Huazhong University of Science and Technology, No. 13 Hangkong Road, Wuhan 430030, China

Full list of author information is available at the end of the article
}

method was available for diabetes, the disease and its complications could be prevented, delayed and managed by identifying risk factors and detecting the condition at an early stage [2], and numerous clinical trials have shown that metabolic syndrome (MetS), a cluster of risk factors including abdominal obesity, elevated blood pressure, dyslipidemia and dysglycemia [3], is an important risk factor for DM. MetS was a strong predictor of incident DM [4-6], and which was reported to precede the risk of incidence of DM by as much as 5 years [7]. However, the clinical application and practicality of MetS remained debated $[8,9]$.

(c) The Author(s). 2019 Open Access This article is distributed under the terms of the Creative Commons Attribution 4.0 International License (http://creativecommons.org/licenses/by/4.0/), which permits unrestricted use, distribution, and reproduction in any medium, provided you give appropriate credit to the original author(s) and the source, provide a link to the Creative Commons license, and indicate if changes were made. The Creative Commons Public Domain Dedication waiver (http://creativecommons.org/publicdomain/zero/1.0/) applies to the data made available in this article, unless otherwise stated. 
Although many reports have examined the relationship between MetS and incident DM, there still has been much controversy with regard to certainty of the definition and its value to identify persons with a high risk of DM [10]. It remains an issue whether different definitions of MetS yield similar estimates for risk of DM. Previous study suggested that the risk of DM associated with MetS depended both upon the used definition and the studied population [11]. However, large-scale epidemiology studies were scarce in China [12].

As we all know, obesity and impaired glucose which are included in definition of MetS are two major risk factors for DM [13], and therefore, the MetS should be a risk factor for diabetes. But, there is an ongoing debate as to whether the predictive value of the MetS is mainly attributable to the impaired glucose regulation component. The American Diabetes Association and the European Association for the Study of Diabetes suggested that the association between MetS and DM may due to impaired fasting glucose or impaired glucose tolerance [10]. However, the results from the Framingham Study indicated that trait combinations that did not include fasting glucose also imparted an increased risk for incident DM [14]. Thus, it is necessary to separate the effect of each component of MetS, which is likely to benefit from early intervention strategies.

Thus, we conducted a large-scale epidemiological study in a middle-aged and elderly Chinese population. The objective of this study was to compare the effects of different MetS definitions, including updated International Diabetes Federation (IDF) definition [15], the National Cholesterol Education Program Third Adult Treatment Panel (NCEP ATP III) definition [16] and American Heart Association/National Heart, Lung, and Blood Institute (AHA/NHLBI) definition [17], as well as various components on DM in a Chinese middle-aged and elderly population. Meanwhile, we aimed to explore a more reasonable definition of Mets when analyzing the risk of DM in Chinese population.

\section{Methods}

\section{Study subjects and design}

This data was from China National Stroke Screening and Prevention Project, which was a community-based cross-sectional study that was administrated by the National Project Office of Stroke Prevention and Control and carried out in 30 provinces in mainland China from October 2014 to November 2015. A 2-stage stratified cluster sampling method was used, and 200 project areas were determined firstly in proportion to the local population size and numbers of total counties and in each project area, an urban community and a rural village were selected as primary sampling units according to the geographical environment and suggestions from local hospitals. Cluster sampling method was used in every primary sampling unit and all residents aged $\geq 40$ years were surveyed in primary screening process. Questionnaire survey, physical examination, and risk factors of stroke assessment were conducted in primary health care institutions. A sample of study participants was randomly selected in each primary sampling unit for further survey in laboratory tests, carotid ultrasound, and electrocardiogram. Nevertheless, participants were excluded if they had severe illnesses, and were unable to attend questionnaire survey or physical examination. The present analysis was restricted to individuals who had completed all surveys.

\section{Definition of metabolic syndrome}

An individual was considered to have MetS by the updated IDF definition if he or she fitted the following criteria:

Central obesity (waist circumference $\geq 90 \mathrm{~cm}$ in male and $\geq 80 \mathrm{~cm}$ in female) plus any two of four additional factors: (1) hypertriglyceridemia: Triglyceride (TG) level $\geq$ $1.7 \mathrm{mmol} / \mathrm{L}$; (2) high blood pressure: blood pressure $\geq 130 /$ $85 \mathrm{mmHg}$ or treatment of previously diagnosed hypertension; (3) reduced high-density lipoprotein (HDL)-cholesterol: < $1.03 \mathrm{mmol} / \mathrm{L}$ in males and $1.29 \mathrm{mmol} / \mathrm{L}$ in females or specific treatment for these lipid abnormalities; (4) hyperglycemia: fasting glucose level of $\geq 5.6 \mathrm{mmol} / \mathrm{L}$ or treatment of previously diagnosed type 2 diabetes.

An individual was considered to have MetS by the NCEP ATP IIIdefinition if he or she has three or more of the following criteria:

(1) Central obesity: waist circumference $\geq 102 \mathrm{~cm}$ in male and $\geq 88 \mathrm{~cm}$ in female; (2) high blood pressure: blood pressure $\geq 130 / 85 \mathrm{mmHg}$ or treatment of previously diagnosed hypertension; (3) reduced HDL cholesterol were the same as those of the IDF; (4) hypertriglyceridemia: TG level $\geq 1.7 \mathrm{mmol} / \mathrm{L}$; (5) hyperglycemia: fasting glucose level of $\geq 6.1 \mathrm{mmol} / \mathrm{L}$ or treatment of previously diagnosed type 2 diabetes.

An individual was considered to have MetS by the AHA/NHLBI definition if he or she has three or more of the following criteria:

(1) Central obesity: waist circumference $\geq 90 \mathrm{~cm}$ in male and $\geq 80 \mathrm{~cm}$ in female; (2) high blood pressure: blood pressure $\geq 130 / 85 \mathrm{mmHg}$ or treatment of previously diagnosed hypertension; (3) reduced HDL cholesterol were the same as those of the IDF; (4) hypertriglyceridemia: TG level $\geq 1.7 \mathrm{mmol} / \mathrm{L}$; (5) hyperglycemia: fasting glucose level of $\geq 5.6 \mathrm{mmol} / \mathrm{L}$ or treatment of previously diagnosed type 2 diabetes.

\section{Ascertainment of DM}

DM was assessed according to the diagnosis of physicians. Individuals were defined as DM if they met one of the following criteria: (1) self-reported physician diagnosis of 
DM; (2) self-reported current use of anti-diabetic medication or insulin.

\section{Covariates}

Information on sociodemographic characteristics (age, gender, education, and marital status), lifestyle, chronic diseases history, and physical activity were collected through a questionnaire by face to face interview with trained interviewers. Individuals smoking at least one cigarette per day for more than half a year were defined as current smokers, and those who drink at least one time per week for more than half a year were defined as current drinkers. Physical activity was defined as regularly exercised more than 3 times/weeks and $\geq 30 \mathrm{~min} /$ times or engaged in heavy physical work. Family history of DM diagnosed by physicians was reported by the participants. Body mass index, waistline, systolic blood pressure (SBP), diastolic blood pressure (DBP), triglycerides, total cholesterol, high density lipoproteincholesterol (HDL-C), low density lipoproteincholesterol (LDL $-\mathrm{C}$ ), and fasting glucose were measured using standard procedures.

\section{Data analysis}

The $t$ test and Chi-square test were used to examine differences in continuous and categorical variables between males and females respectively. Logistic regressions were used to calculate odds ratios (ORs) and 95\% confidence intervals (CIs), including the association of different definitions of Mets and DM, and the relationship of various components of Mets and DM. We chose covariates according to evidence from published literatures $[18,19]$. Potential confounders included age, gender, marital status, level of education, current smoking, current drinking, physical activity, and family history of diabetes mellitus. All analyses were conducted using SPSS 19.0 (SPSS Inc., Chicago, Ill). The statistical tests were two sided, and significance was set at $P<0.05$.

\section{Results}

The present study included 109,551participants. Table 1 showed the basic characteristics of the 109,551 subjects (49,789 men and 59,762 women). Among them, a total of 15,799 individuals had diabetes mellitus, including 6799 males (13.7\%) and 9000 females (15.1\%). Small but statistically significant differences were found between men and women in other demographic, anthropometric and clinical characteristics. Interesting, the difference was significant in DM $(P<0.001)$, but not for BMI $(P=0.306)$ and fasting glucose $(P=0.292)$.

Table 2 showed the estimated association of DM and MetS or components of MetS by different MetS criteria. The MetS was significantly associated with DM and the ORs of the disease associated with MetS defined by ATP was greater $(\mathrm{OR}=3.65,95 \% \mathrm{CI}=3.52-3.79)$ than the other two criteria with the adjustment of covariates $(\mathrm{OR}=3.03,95 \% \mathrm{CI}=2.92-3.14$ for $\mathrm{AHA} / \mathrm{NHLBI}, \mathrm{OR}=$ $2.50,95 \% \mathrm{CI}=2.41-2.60$ for IDF). When the MetS criteria were combined, it indicated that the odds of DM was highest based on MetS by AHA/NHLBI and NCEP ATP III (OR $=3.65,95 \% \mathrm{CI}=3.52-3.79)$, compared with nonMetS individuals when adjusting for other variables. As to the MetS components, it revealed that the number of MetS components was related with DM in a dose-response way, regardless of different definitions of MetS. And five components of MetS by NCEP ATP III got the highest risk $(\mathrm{OR}=26.40,95 \% \mathrm{CI}=22.90-30.43)$.

Table 3 showed the effects of various combinations of MetS traits on DM according to the presence of single component and their combination in pairs, triplets and quartets. The OR of DM associated with specific trait combinations was estimated with the group without that specific combination used as the comparator. The analysis suggested that heterogeneity for DM associated with various trait combinations. In terms of single component, hyperglycemia (glucose $\geq 6.1$ ) was associated with the highest prevalence of DM $(\mathrm{OR}=14.55,95 \% \mathrm{CI}=13.97-15.16)$, two components (hyperglycemia (glucose $\geq 6.1$ ) and elevated $\mathrm{BP})$ was associated with the highest prevalence of DM $(\mathrm{OR}=9.90,95 \% \mathrm{CI}=9.50-10.30)$, three components (hyperglycemia (glucose $\geq 6.1$ ), central obesity (waist $\geq 90 / 80$ ) and elevated $\mathrm{BP}$ ) was associated with the highest prevalence of DM (OR $=7.45,95 \% \mathrm{CI}=7.14-7.78)$, four components (hyperglycemia (glucose $\geq 6.1$ ), hypertriglyceridemia, central obesity (waist $\geq 90 / 80$ ) and elevated BP) was associated with the highest prevalence of $\mathrm{DM}(\mathrm{OR}=5.83$, 95\% CI $=5.52-6.15)$. Besides, the analyses based on different combinations indicated that the OR of DM was higher in the combination including hyperglycemia (glucose $\geq 6.1$ ) than other combinations.

\section{Discussions}

In the present study, MetS as defined by three criteria all increased the prevalence of DM in Chinese middle-aged and elderly population, thus it verified that MetS was an important risk factor for DM among Chinese population. However, the three MetS definition did not seem to yield the same estimates for risk of DM and the NCEP ATP III MetS definition may be more suitable for assessment of DM risk with the highest increased risk of DM. To our knowledge, it is the first study to compare different definitions and components of MetS when assessing its relationship with DM in a large Chinese population. The results of our study could provide a reference when the MetS definition was conducted among Chinese adults.

Our study also showed that hyperglycemia was significantly associated with an increased risk of DM after adjusting for sex, age, marital status, education, physical activity, current smoking, current drinking, and family 
Table 1 Demographic, Anthropometric, and Plasma Biochemical Characteristics of Subjects

\begin{tabular}{|c|c|c|c|}
\hline Characteristic & Male $(n=49,789)$ & Female $(n=59,762)$ & $P$ Value \\
\hline Mean age(mean, SD),years & $59.15 \pm 11.150$ & $59.30 \pm 10.894$ & 0.028 \\
\hline \multicolumn{4}{|l|}{ Age, years } \\
\hline $40 \sim 49$ & $11,842(23.8)$ & $13,095(21.9)$ & \multirow[t]{3}{*}{$<0.001$} \\
\hline $50 \sim 59$ & $13,872(27.9)$ & $17,504(29.3)$ & \\
\hline$\geq 60$ & $24,075(48.4)$ & $29,163(48.8)$ & \\
\hline \multicolumn{4}{|l|}{ Education } \\
\hline Primary school and below & $17,504(35.2)$ & $28,786(8.2)$ & \multirow[t]{4}{*}{$<0.001$} \\
\hline Middle school & $19,277(38.7)$ & $19,018(31.8)$ & \\
\hline High school or the equivalent & $8339(16.7)$ & $8623(14.4)$ & \\
\hline University or other tertiary degree & $4669(9.4)$ & $3335(5.6)$ & \\
\hline \multicolumn{4}{|l|}{ Marital status } \\
\hline Married & $47,467(95.3)$ & $54,729(91.6)$ & \multirow[t]{3}{*}{$<0.001$} \\
\hline Single or divorced & $1001(2.0)$ & $844(1.4)$ & \\
\hline Widowed & $1321(2.7)$ & $4189(7.0)$ & \\
\hline Physical activity $^{\mathrm{a}}$ & $37,637(75.6)$ & $44,241(74.0)$ & $<0.001$ \\
\hline Smokers & $21,378(42.9)$ & $2196(3.7)$ & $<0.001$ \\
\hline Drinkers & $13,581(27.3)$ & $1485(2.5)$ & $<0.001$ \\
\hline Diabetes mellitus & $6799(13.7)$ & $9000(15.1)$ & $<0.001$ \\
\hline Family history of diabetes mellitus & $2904(5.8)$ & $3839(6.4)$ & $<0.001$ \\
\hline Anti-diabetic medication in two weeks & $4282(8.6)$ & $5663(9.5)$ & $<0.001$ \\
\hline Body mass index(mean, SD) & $24.87 \pm 3.520$ & $24.90 \pm 3.809$ & 0.306 \\
\hline Waistline (cm) (mean, SD) & $87.55 \pm 10.45$ & $84.19 \pm 10.45$ & $<0.001$ \\
\hline Waist circumference $(\mathrm{cm})(\mathrm{NCEP}$ ATPIII and AHA/NHLBI) & $3608(7.2)$ & $20,215(33.8)$ & $<0.001$ \\
\hline Waist circumference $(\mathrm{cm})(\mathrm{IDF})^{\mathrm{c}}$ & $19,964(40.1)$ & $40,999(68.6)$ & $<0.001$ \\
\hline Systolic blood pressure(mmHg) & $134.94 \pm 18.47$ & $134.00 \pm 19.85$ & $<0.001$ \\
\hline Diastolic blood pressure $(\mathrm{mmHg})$ & $83.23 \pm 11.30$ & $81.44 \pm 11.21$ & $<0.001$ \\
\hline Triglycerides(mmol/l) & $1.76 \pm 1.36$ & $1.73 \pm 1.18$ & 0.003 \\
\hline Total cholesterol(mmol/l) & $4.77 \pm 1.09$ & $5.01 \pm 1.15$ & $<0.001$ \\
\hline $\mathrm{HDL}$ cholesterol $(\mathrm{mmol} / \mathrm{l})$ & $1.43 \pm 0.61$ & $1.50 \pm 0.57$ & $<0.001$ \\
\hline LDL cholesterol(mmol/l) & $2.80 \pm 0.93$ & $2.92 \pm 0.97$ & $<0.001$ \\
\hline Fasting glucose(mmol/L) & $5.76 \pm 1.76$ & $5.75 \pm 1.77$ & 0.292 \\
\hline Fasting glucose $(\mathrm{mmol} / \mathrm{l})(\mathrm{NCEP}$ ATP III) & $11,353(22.8)$ & $13,242(22.2)$ & 0.011 \\
\hline Fasting glucose $(\mathrm{mmol} / \mathrm{I})(\mathrm{AHA} / \mathrm{NHLBI}$ and IDF) & $19,846(39.9)$ & $23,158(38.8)$ & $<0.001$ \\
\hline
\end{tabular}

${ }^{\mathrm{a}}$ Times of physical activity $\geq 3 /$ weeks and $\geq 30 \mathrm{~min} /$ times or the person is an industrial/argricular labor; ${ }^{\mathrm{b}}$ waist circumference $\geq 102 \mathrm{~cm}$ in male and $\geq 88 \mathrm{~cm}$ in female; ${ }^{c}$ waist circumference $\geq 90 \mathrm{~cm}$ in male and $\geq 80 \mathrm{~cm}$ in female; ${ }^{d}$ fasting glucose level of $\geq 5.6 \mathrm{mmol} / \mathrm{L}$; ${ }^{e}$ fasting glucose level of $\geq 6.1 \mathrm{mmol} / \mathrm{L}$ SD standard deviation, NCEP ATPIII National Cholesterol Education Program Third Adult Treatment Panel, AHA/NHLBI American Heart Association/National Heart, Lung, and Blood Institute, IDF International Diabetes Federation, HDL high-density lipoprotein, $L D L$-low density lipoprotein

history of DM. Previous studies suggested impaired fasting glucose (IFG) was the strongest predictor of type 2 diabetes among the components [20-22], which was also confirmed in our study, the hyperglycemia with cut-off $\geq 6.1 \mathrm{mmol} / \mathrm{L}$ was associated with the highest prevalence of DM in all components. Besides, hypertriglyceridemia was also associated with increased risk of DM after adjusting confounding factors in the present study. Raised plasma triglyceride is thought to play a role in the pathogenesis of insulin-resistant diabetes and may be used as a biomarker for the prediction of risk of type 2 diabetes [23]. Some experimental studies [24] and human case reports also supported that hypertriglyceridemia could predict insulin resistance and glucose intolerance and showed that insulin-resistant diabetes could be caused by extremely high levels of triglycerides [25].

Central obesity, defined as an essential component in some MetS diagnostic criteria, such as those of the IDF [3] 
Table 2 Odds and 95\% Confidence Interval (Cl) of Diabetes Mellitus for MetS and the Number of Components of MetS by the NCEP, AHA and IDF Criteria

\begin{tabular}{|c|c|c|}
\hline & \multicolumn{2}{|l|}{$\operatorname{DM}(n=15,799)$} \\
\hline & Crude OR(95\% Cl) & $\operatorname{AdjOR}(95 \% \mathrm{Cl})$ \\
\hline \multicolumn{3}{|l|}{ MetS by different criteria(Ref. $=$ Non-MetS) } \\
\hline NCEP ATP III & $4.12(3.98-4.26)$ & $3.65(3.52-3.79)$ \\
\hline $\mathrm{AHA} / \mathrm{NHLBI}$ & $3.46(3.34-3.58)$ & $3.03(2.92-3.14)$ \\
\hline IDF & $2.84(2.74-2.93)$ & $2.50(2.41-2.60)$ \\
\hline \multicolumn{3}{|l|}{ Subgroup of MetS(Ref. = Non-MetS) } \\
\hline MetS by IDF and NCEP ATP III & $4.96(4.77-5.17)$ & $3.06(2.94-3.18)$ \\
\hline MetS by IDF and AHA/NHLBI & $4.33(4.16-4.51)$ & $2.63(2.53-2.73)$ \\
\hline MetS by AHA/NHLBI and NCEP ATP III & $4.11(3.97-4.26)$ & $3.65(3.52-3.79)$ \\
\hline \multicolumn{3}{|c|}{ Nunber of components of MetS by NCEP ATP III(Ref.= zero) } \\
\hline One & $2.08(1.87-2.32)$ & $1.78(1.59-1.98)$ \\
\hline Two & $5.24(4.74-5.81)$ & $4.35(3.93-4.83)$ \\
\hline Three & $9.84(8.88-10.91)$ & $7.86(7.08-8.72)$ \\
\hline Four & $18.24(16.38-30.31)$ & $13.93(12.47-15.56)$ \\
\hline Five & $34.42(30.03-39.46)$ & $26.40(22.90-30.43)$ \\
\hline$P$ for trend & & $<0.001$ \\
\hline \multicolumn{3}{|c|}{ Nunber of components of MetS by AHA/NHLBI(Ref. = zero) } \\
\hline One & $2.48(2.19-2.82)$ & $2.11(1.86-2.40)$ \\
\hline Two & $6.12(5.42-6.90)$ & $4.93(4.36-5.57)$ \\
\hline Three & $10.60(9.39-11.97)$ & $8.17(7.23-9.24)$ \\
\hline Four & $17.19(15.18-19.46)$ & $12.60(11.10-14.30)$ \\
\hline Five & $26.18(22.70-30.20)$ & $19.10(16.41-22.03)$ \\
\hline$P$ for trend & & $<0.001$ \\
\hline \multicolumn{3}{|c|}{ Nunber of components of MetS by IDF(Ref. = zero $)$} \\
\hline One & $2.28(1.95-2.67)$ & $2.01(1.72-2.36)$ \\
\hline Two & $4.70(4.308-5.46)$ & $3.88(3.33-4.52)$ \\
\hline Three & $9.432(8.13-10.95)$ & 7.406.36-8.61) \\
\hline Four & $14.65(12.60-17.03)$ & $11.06(9.49-12.88)$ \\
\hline Five & $26.57(22.69-31.12)$ & $18.81(16.01-22.10)$ \\
\hline$P$ for trend & & $<0.001$ \\
\hline
\end{tabular}

Adjusted for sex, age $(40 \sim 49,50 \sim 59, \geq 60)$, marital status, education, physical activity ( 3 times/weeks and $\geq 30 \mathrm{~min} /$ times or is industrial and agricular labor), current smoking (yes, no), current drinking (yes, no), family history of diabetes mellitus

MetS metabolic syndrome, NCEP ATPIII National Cholesterol Education Program Third Adult Treatment Panel, AHA/NHLBI American Heart Association/National Heart, Lung, and Blood Institute, IDF International Diabetes Federation, HDL high-density lipoprotein, Ref reference

For NCEP ATP III criterion, component one to five are one or more of five components including central obesity (waist $\geq 102 / 88$ ), elevated BP, hypertriglyceridemia, low HDL and hyperglycemia (glucose $\geq 6.1$ ); For AHA/NHLBI criterion, component one to five are one or more of five components including central obesity (waist $\geq 102 / 88$ ), elevated BP, hypertriglyceridemia, low HDL and hyperglycemia (glucose $\geq 5.6$ ); For IDF criterion, component one to five are one or more of five components including central obesity (waist $\geq 90 / 80$ ), hypertriglyceridemia, elevated BP, low HDL and hyperglycemia (glucose $\geq 5.6$ )

or the Japanese criteria [26], has been reported to be an important factor in the development of DM [27]. Besides, our results also showed central obesity was not the indispensable component of MetS for the risk of DM. Other components such as elevated BP and low HDL cholesterol yield similar effect on prevalence of $\mathrm{DM}$, and a previous studies have shown that elevated $\mathrm{BP}$ and low HDL cholesterol were associated with insulin resistance [28] and therefore may contributed to the occurrence of DM. The results also indicated the importance of blood pressure in the prevention and management of DM $[29,30]$. It was consistent with a previous longitudinal study [31], which showed the incidence of T2DM was higher among individuals with higher BP and low HDL cholesterol level. However, no causal association between low HDL cholesterol levels and T2DM was found in another prospective study [32]. Our results supported that the MetS, as a risk 


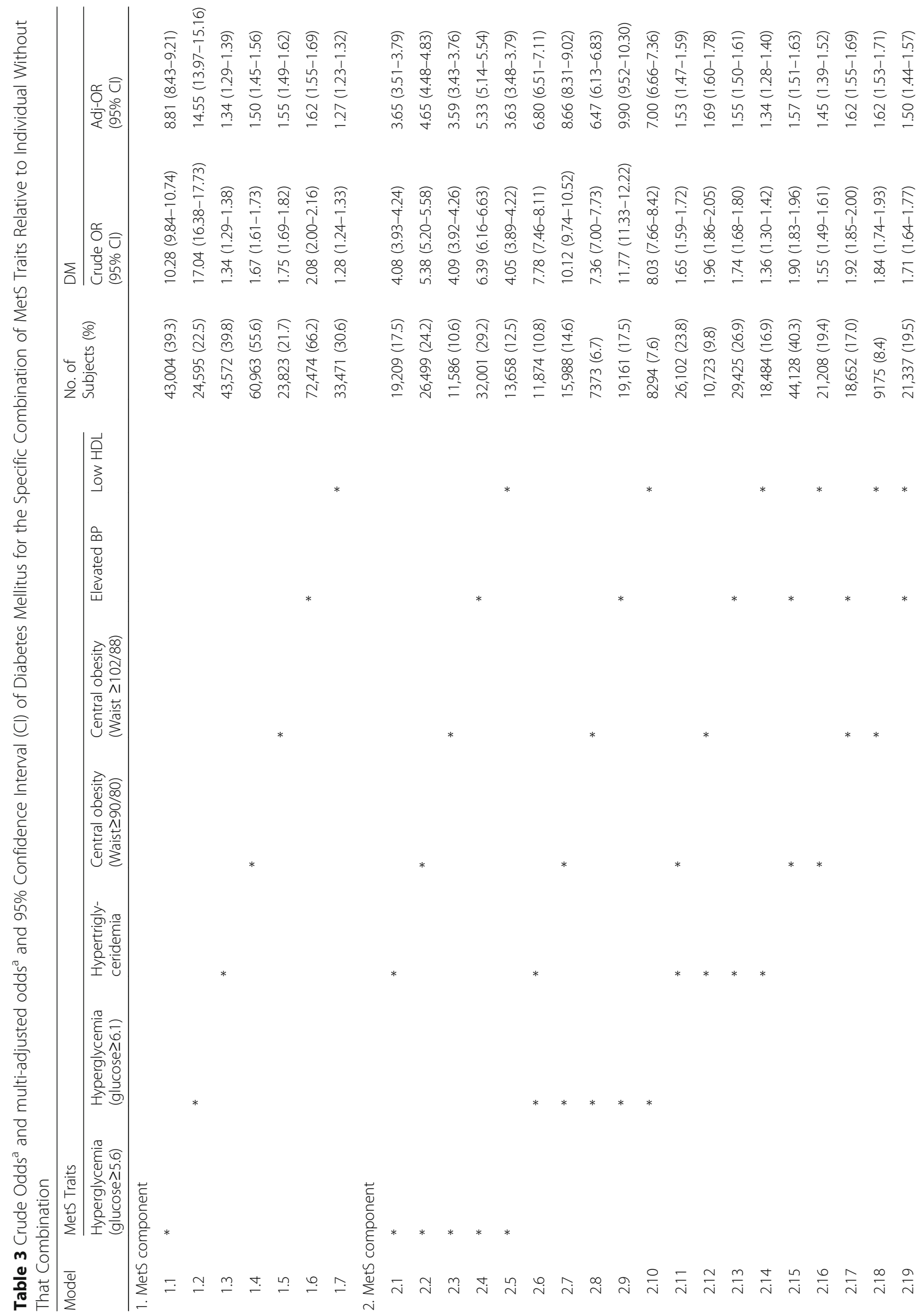




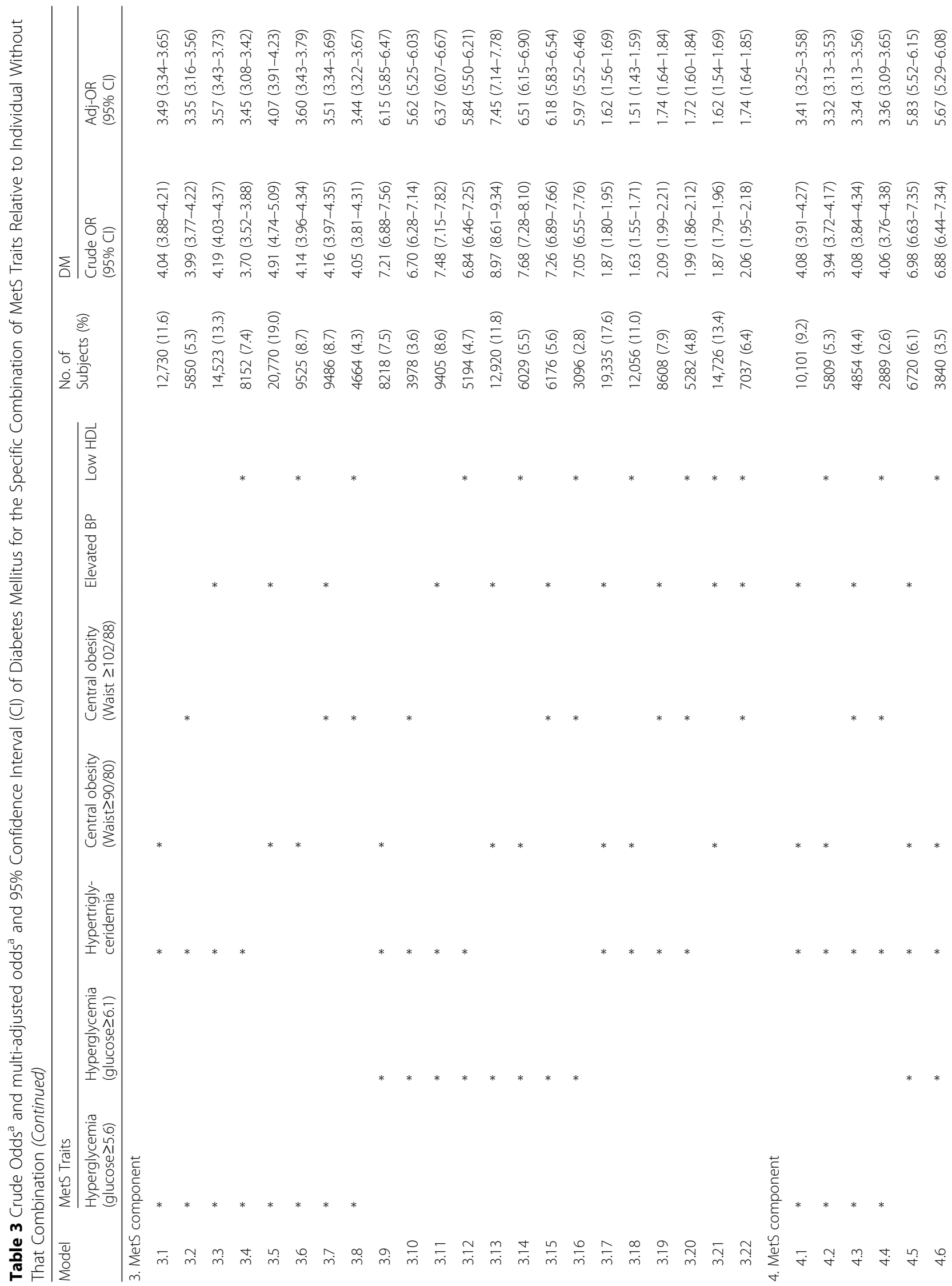




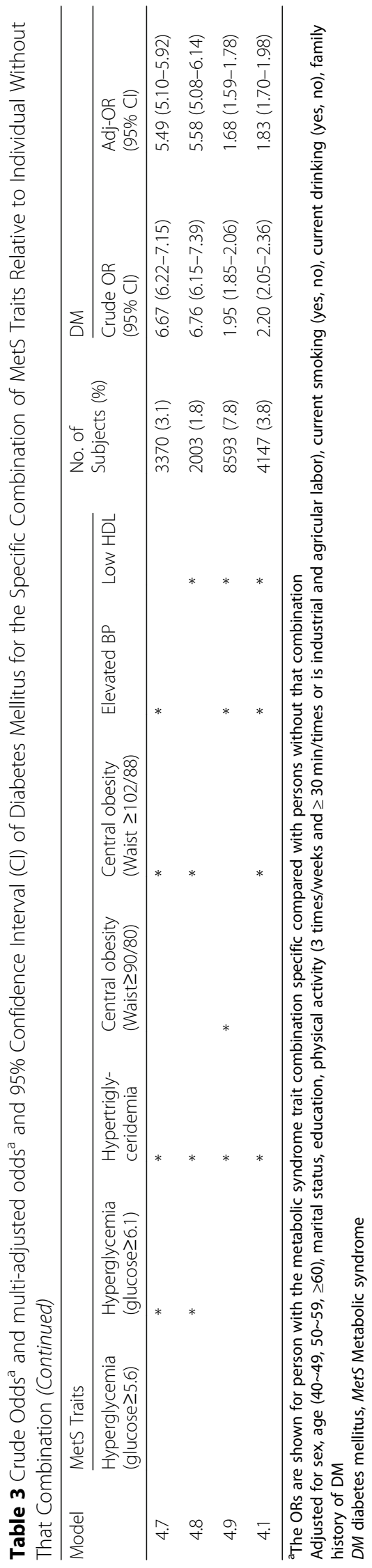


factor of DM, should be considered as a clinical entity independent of prediabetes or DM [33].

Epidemiological studies revealed that the risk of multiple risk factors was much more than the sum of accompanying single risk factors [34], and whether the risk of MetS was greater than the sum of its individual components that came up in cardiovascular field has been debated [35]. Thus, we further explored the relationship between different trait combinations and risk of DM, and we found that there were differences of associations of trait combinations of MetS with DM, which may result from the different pathological mechanisms and the interactive effects of components. A study with 1844 subjects showed IFG added with two or more other components apparently increased the risk of DM compared to IFG alone [36], but the effects did not seem to be observed in our results. The differences in study design, study population, study sample and adjusted confounders, etc. may contribute to the different results. Further studies with larger sample and longer follow-up time cohort study should be conducted to examine the results.

With the aging, industrialization, economic transition and sedentary lifestyle, there was a striking increase in the number of individuals with MetS in China [37]. A survey [38] performed in 97,098 Chinese residents from 31 provinces showed the prevalence of the MetS was 33.9\%, which will result in the increased risk of DM inevitably due to significant association of them, therefore, developing effective public health strategies for the control and treatment of MetS should be an urgent priority to reduce the social and medical burden of DM in China.

Some limitations of the study are worth mentioning. First of all, the study is a cross-sectional study and limits to confirm the causal inference, which is a main limitation in epidemiological studied in general. Secondly, DM and other confounders were self-reported, which may have led to misclassification and underestimated or over-estimated the association of MetS with the risk of DM. In addition, although our analyses were adjusted for smoking and alcohol consumption, residual confounders remain due to lifestyle factors could not be excluded. Thirdly, the measured glucose was just fasting glucose, not the 2-h post-meal glucose or HbA1c, which may influence the results. Fourthly, communities and villages were selected as primary sampling units according to suggestions from local hospitals in the present study, although it was a practical and more reliable approach, subjective problem may be not excluded. Last but not least, we could not distinguish the type $1 \mathrm{DM}$ and type $2 \mathrm{DM}$ due to data limitation, which should be explored in the future study.

\section{Conclusions}

Our study suggests that the MetS defined by three criteria were associated with DM, and the NCEP ATP III
MetS definition may be more suitable for assessment of DM risk than other two definitions in Chinese population. Besides, other traits of MetS and their combinations are also significantly associated with DM and should therefore be more concerned as soon as possible so as to change the growing trend of MetS and DM in China. Further studies with all ages and different ethnic groups should be conducted in the future.

\section{Abbreviations \\ AHA/NHLBI: American Heart Association/National Heart, Lung, and Blood Institute; Cl: Confidence interval; DBP: Diastolic blood pressure; DM: Diabetes mellitus; HDL : High-density lipoprotein; HDL-C: Lipoproteincholesterol; IDF: International Diabetes Federation; LDL -C: Low density lipoproteincholesterol; MetS: Metabolic syndrome; NCEP ATP III: National Cholesterol Education Program Third Adult Treatment Panel; OR: Odds ratio; SBP: Systolic blood pressure; TG: Triglyceride}

\section{Acknowledgements}

None

\section{Funding}

This work was supported by the Ministry of Finance of the People's Republic of China (Issued by Finance and Social Security [2011] Document No. 61, Ministry of Finance) the Fundamental Research Funds for the Central Universities, Huazhong University of Science and Technology, Wuhan, China. (2016YXMS215) and the Innovation Committee of Shenzhen Science and Technology, "Demonstration Application of Cardiovascular and Cerebrovascular Disease Prevention and Control Based on Functional Community" (KJYY20170413162318686). The funders did not play any role in study design; in the collection, analysis, and interpretation of data; in the writing of the report; nor in the preparation, review, or approval of the manuscript. This study was supported by Research on the Construction of China's Graded Medical System under the Shared Economy (18ZDA085).

\section{Availability of data and materials}

The data that support the findings of this study are available from National Project Office of Stroke Prevention and Control but restrictions apply to the availability of these data, which were used under license for the current study, and so are not publicly available. Data are however available from the authors upon reasonable request and with permission of National Project Office of Stroke Prevention and Control.

\section{Authors' contributions}

XJW, WHS, XBZ helped conduct the survey and build the dataset. WZL analyzed the data and wrote the draft of the paper, DMW, YHG, SYC and $X X Y$ revised and edited the paper. XJW contributed to the discussion. ZHW and ZXL made substantial contributions to conception and design. All authors have read and approved the manuscript.

\section{Ethics approval and consent to participate}

The study protocol was approved by the Ethics committee of the XuanWu hospital Institutional review Board, Capital Medical University (Beijing, China). Written informed consent was obtained from all participants for entry into the database and use of their data for research.

\section{Consent for publication}

Not applicable.

\section{Competing interests}

Ethics approval and consent to participate.

\section{Publisher's Note}

Springer Nature remains neutral with regard to jurisdictional claims in published maps and institutional affiliations. 


\section{Author details}

${ }^{1}$ Department of Social Medicine and Health Management, School of Public Health, Tongji Medical College, Huazhong University of Science and Technology, No. 13 Hangkong Road, Wuhan 430030, China. ${ }^{2}$ Department of Occupational \& Environmental Health, School of Public Health, Tongji Medical College, Huazhong University of Science and Technology, Wuhan 430030, China. ${ }^{3}$ Department of Neurology, Liaocheng People's Hospital, Liaocheng city, Shandong Province, China. ${ }^{4}$ Department of science and education, The Third Hospital of Shijiazhuang, Shijiazhuang city, Hebei Province, China. ${ }^{5}$ Health Science Center, Shenzhen second people's hospital, The First Affiliated Hospital of Shenzhen University, Shenzhen 518020, People's Republic of China. 'Shenzhen, China.

\section{Received: 19 September 2018 Accepted: 8 January 2019} Published online: 14 February 2019

\section{References}

1. Wild S, Roglic G, Green A, Sicree R, King H. Global prevalence of diabetes: estimates for the year 2000 and projections for 2030. Diabetes Care. 2004; 27(5):1047-53.

2. Stumvoll M, Goldstein BJ, van Haeften TW. Type 2 diabetes: principles of pathogenesis and therapy. Lancet. 2005;365(9467):1333-46.

3. Eckel RH, Grundy SM, Zimmet PZ. The metabolic syndrome. Lancet. 2005; 365(9468):1415-28.

4. Hadaegh F, Ghasemi A, Padyab M, Tohidi M, Azizi F. The metabolic syndrome and incident diabetes: assessment of alternative definitions of the metabolic syndrome in an Iranian urban population. Diabetes Res Clin Pract. 2008;80(2):328-34

5. Sacco S, Comelli M, Molina V, Montrasio PL, Giani E, Cavanna F. A simplified indication of metabolic syndrome to recognize subjects with a moderate risk to develop type 2 diabetes mellitus in a large Italian sample. Acta Diabetol. 2014,51(1):35-41.

6. Sattar N, McConnachie A, Shaper AG, Blauw GJ, Buckley BM, de Craen AJ, Ford I, Forouhi NG, Freeman DJ, Jukema JW, et al. Can metabolic syndrome usefully predict cardiovascular disease and diabetes? Outcome data from two prospective studies. Lancet. 2008;371(9628):1927-35.

7. Klein $B E$, Klein $\mathrm{R}$, Lee KE. Components of the metabolic syndrome and risk of cardiovascular disease and diabetes in beaver dam. Diabetes Care. 2002; 25(10):1790-4.

8. Alberti KG, Zimmet PZ. Should we dump the metabolic syndrome? No. BMJ. 2008;336(7645):641.

9. Gale EA. Should we dump the metabolic syndrome? Yes. BMJ. 2008; 336(7645):640

10. Kahn R, Buse J, Ferrannini E, Stern M. The metabolic syndrome: time for a critical appraisal. Joint statement from the American Diabetes Association and the European Association for the Study of diabetes. Diabetologia. 2005; 48(9):1684-99.

11. Ford ES. Risks for all-cause mortality, cardiovascular disease, and diabetes associated with the metabolic syndrome: a summary of the evidence. Diabetes Care. 2005;28(7):1769-78.

12. Zeng $P$, Zhu X, Zhang Y, Wang S, Zhang T. Metabolic syndrome and the development of type 2 diabetes among professionals living in Beijing, China. Diabetes Res Clin Pract. 2011;94(2):299-304.

13. Noale M, Maggi S, Marzari C, Limongi F, Gallina P, Bianchi D, Crepaldi G. Components of the metabolic syndrome and incidence of diabetes in elderly Italians: the Italian longitudinal study on aging. Atherosclerosis. 2006; 187(2):385-92

14. Wilson PW, D'Agostino RB, Parise H, Sullivan L, Meigs JB. Metabolic syndrome as a precursor of cardiovascular disease and type 2 diabetes mellitus. Circulation. 2005;112(20):3066-72.

15. Alberti KG, Zimmet $P$, Shaw J. The metabolic syndrome--a new worldwide definition. Lancet. 2005;366(9491):1059-62.

16. Expert Panel on Detection, Evaluation, and Treatment of High Blood Cholesterol in Adults. Executive Summary of The Third Report of The National Cholesterol Education Program (NCEP) Expert Panel on Detection, Evaluation, And Treatment of High Blood Cholesterol In Adults (Adult Treatment Panel III). Jama. 2001;285(19):2486-97.

17. Grundy SM, Cleeman JI, Daniels SR, Donato KA, Eckel RH, Franklin BA, Gordon DJ, Krauss RM, Savage PJ, Smith SC Jr, et al. Diagnosis and management of the metabolic syndrome: an American Heart Association/
National Heart, Lung, and Blood Institute scientific statement. Circulation. 2005;112(17):2735-52.

18. Ayubi E, Khalili D, Delpisheh A, Hadaegh F, Azizi F. Factor analysis of metabolic syndrome components and predicting type 2 diabetes: results of 10-year follow-up in a middle eastern population. J Diabetes. 2015;7(6):830-8.

19. Xu H, Song Y, You NC, Zhang ZF, Greenland S, Ford ES, He L, Liu S. Prevalence and clustering of metabolic risk factors for type 2 diabetes among Chinese adults in Shanghai, China. BMC public health. 2010;10:683.

20. Mukai N, Doi Y, Ninomiya T, Hata J, Yonemoto K, Iwase M, lida M, Kiyohara Y. Impact of metabolic syndrome compared with impaired fasting glucose on the development of type 2 diabetes in a general Japanese population: the Hisayama study. Diabetes Care. 2009:32(12):2288-93.

21. Nichols GA, Moler EJ. Diabetes incidence for all possible combinations of metabolic syndrome components. Diabetes Res Clin Pract. 2010;90(1):115-21.

22. Ford ES, Schulze MB, Pischon T, Bergmann MM, Joost HG, Boeing H. Metabolic syndrome and risk of incident diabetes: findings from the European prospective investigation into Cancer and nutrition-Potsdam study. Cardiovasc Diabetol. 2008;7:35.

23. Aslam M, Aggarwal S, Sharma KK, Galav V, Madhu SV. Postprandial hypertriglyceridemia predicts development of insulin resistance glucose intolerance and type 2 diabetes. PLoS One. 2016;11(1):e0145730.

24. Samuel VT, Liu ZX, Qu X, Elder BD, Bilz S, Befroy D, Romanelli AJ, Shulman $\mathrm{Gl}$. Mechanism of hepatic insulin resistance in non-alcoholic fatty liver disease. J Biol Chem. 2004;279(31):32345-53.

25. Mingrone G, Henriksen FL, Greco AV, Krogh LN, Capristo E, Gastaldelli A Castagneto M, Ferrannini E, Gasbarrini G, Beck-Nielsen H. Triglycerideinduced diabetes associated with familial lipoprotein lipase deficiency. Diabetes. 1999;48(6):1258-63.

26. Definition and the diagnostic standard for metabolic syndrome--Committee to Evaluate Diagnostic Standards for Metabolic Syndrome. Nihon Naika Gakkai zasshi. 2005;94(4):794-809.

27. Mamtani MR, Kulkarni HR. Predictive performance of anthropometric indexes of central obesity for the risk of type 2 diabetes. Arch Med Res. 2005:36(5):581-9.

28. Reaven GM. Role of insulin resistance in human disease (syndrome X): an expanded definition. Annu Rev Med. 1993:44:121-31.

29. Norgaard SK, Vestgaard MJ, Jorgensen IL, Asbjornsdottir B, Ringholm L, McIntyre HD, Damm P, Mathiesen ER. Diastolic blood pressure is a potentially modifiable risk factor for preeclampsia in women with preexisting diabetes. Diabetes Res Clin Pract. 2018;138:229-37.

30. McAlister FA, Lethebe BC, Lambe C, Williamson T, Lowerison M. Control of glycemia and blood pressure in British adults with diabetes mellitus and subsequent therapy choices: a comparison across health states. Cardiovasc Diabetol. 2018;17(1):27

31. Marott SC, Nordestgaard BG, Tybjaerg-Hansen A, Benn M. Components of the metabolic syndrome and risk of type 2 diabetes. J Clin Endocrinol Metab. 2016:101(8):3212-21.

32. Haase $C L$, Tybjaerg-Hansen A, Nordestgaard BG, Frikke-Schmidt R. HDL cholesterol and risk of type 2 diabetes: a Mendelian randomization study. Diabetes. 2015;64(9):3328-33.

33. Uzunlulu M, Oguz A. Is metabolic syndrome a condition independent of prediabetes and type 2 diabetes mellitus? A report from Turkey. Endocr J. 2007:54(5):745-50.

34. Grundy SM. Metabolic syndrome: connecting and reconciling cardiovascular and diabetes worlds. J Am Coll Cardiol. 2006;47(6):1093-100.

35. Kahn R, Buse J, Ferrannini E, Stern M. The metabolic syndrome: time for a critical appraisal: joint statement from the American Diabetes Association and the European Association for the Study of diabetes. Diabetes Care. 2005;28(9):2289-304

36. Liu SJ, Guo ZR, Hu XS, Wu M, Chen FM, Kang GD, Zhou H, Guo L. Risks for type-2 diabetes associated with the metabolic syndrome and the interaction between impaired fasting glucose and other components of metabolic syndrome the study from Jiangsu, China of 5 years follow-up. Diabetes Res Clin Pract. 2008;81(1):117-23.

37. Zimmet P, Alberti KG, Shaw J. Global and societal implications of the diabetes epidemic. Nature. 2001;414(6865):782-7.

38. Lu J, Wang L, Li M, Xu Y, Jiang Y, Wang W, Li J, Mi S, Zhang M, Li Y, et al. Metabolic Syndrome among Adults in China - The 2010 China Noncommunicable Disease Surveillance. J Clin Endocrinol Metab. 2016: jc20162477. 